\title{
The Volume of Vehicular Greenhouse gas Emissions along a Dual Carriage Road in North-Central Nigeria: A Survey Study
}

\author{
Elizabeth D. Ebeshi", Olusegun Ekanade \\ Department of Geography, Faculty of Social Science, Nasarawa State University, Keffi, Nigeria
}

"Corresponding Author: Elizabeth D. Ebeshi, Department of Geography, Faculty of Social Science, Nasarawa State University, Keffi, Nigeria

\begin{abstract}
Vehicular traffic contributes immensely to urban air pollution and its subsequent impact on human health in both the developed and the less developed countries, Nigeria inclusive. The objectives of the study were to measure the concentration of some greenhouse gases, largely products of internal combustion in motor vehicle engines namely: nitrogen dioxide $\left(\mathrm{NO}_{2}\right)$, sulphur dioxide $\left(\mathrm{SO}_{2}\right)$, carbon monoxide $(\mathrm{CO})$, particulate matter and noise at the study location during traffic peak and lean periods as well as compare the result of the greenhouse gases during peak and lean periods with acceptable limits. In doing this, air quality assessment was also carried out using the hand-held Orion multiple gas alerts, $\mathrm{CO}, \mathrm{NO}_{2}$ and $\mathrm{SO}_{2}$, respectively. Measurements were taken during traffic peak periods between 7:00am and 10:00am while the off-peak measurements were taken between 12:00pm and 3:00pm. Number of vehicles were counted at mornings, and evenings to know the influx of cars into the city and out of the city, thus to compare the number of vehicles that ply the area with vehicular emissions. The findings of the study revealed that the concentration of these greenhouse gases is more during traffic peak periods than the lean periods. Therefore, measures that seek to minimize emission of pollutants from automobile are urgently required in major cities of the developing countries.
\end{abstract}

Keywords: Vehicular Traffic, Dual-carriage way, Greenhouse gases, North central Nigeria

Abbreviations: CO: Carbon monoxide, CO2: Carbon dioxide, SO2: Sulphur dioxide, NO2: Nitogen dioxide, NO: Nitrous oxide, PM: Particulate matter, FCT: Federal Capital Territory, ppm: parts per million, IPCC: Intergovernmental Panel on Climate Change, NISER: Nigerian Institute of Social and Economic Research, USEPA: United States Environmental Protection Agency, WADSCO: Water and Dam Services Company

\section{INTRODUCTION}

Traffic-related emissions are a complex mix of pollutants comprised of nitrogen oxides (including nitrogen dioxide), particulate matter, carbon monoxide, sulphur dioxide, volatile organic compounds, ozone, and many other chemicals such as trace toxics and greenhouse gases $\left(\mathrm{CO}_{2}, \mathrm{NO}_{2}, \mathrm{SO}_{2}, \mathrm{PM}\right)$. This concentration of pollutants varies both spatially and temporally. Exposure to pollutants is elevated in urban areas with high traffic volumes and heavy traffic highway corridors [1,2]. High levels of vehicle-related emissions have been linked to high density traffic sites [3]. Street canons (streets lined with tall buildings that impede the dispersion of air pollutant) and areas very close to busy roads typically have a high concentration of emissions [4-6].

These areas may also contain a high concentration of people, including pedestrians and cyclists, or people within buildings alongside the road. Individual drivers or passengers of cars are also exposed to vehicle-related emissions. Individuals at all stages of their life are at risk with traffic pollution. However, the severity of the hazard varies with age and underlying medical conditions. The extent to which people are exposed to air pollution depends on a variety of factors, such as being inside a vehicle, working or living close to traffic, physical activity level, duration of exposure, stage of life and health status [7].

Abuja the Capital City of Nigeria has experienced and is still experiencing huge population growth. It has been reported that some areas around have been growing at $20 \%$ to $30 \%$ per year. Squatters' settlements and towns have spread rapidly in and outside the city limits. The current population of the city is higher than ultimate level projected when all phases are completed [8]. The number of vehicles 
for private and public purposes has also increased tremendously; this situation has led to traffic congestion in the city centers and the suburbs. So more with the escalating rental prices for houses in the Abuja main city and high cost of living, residents, most especially low income earners have to sort for cheaper accommodation in the suburbs such as, Gwagwalada, Karu, Kubwa, Nyanya etc, a phenomenon that has given rise to population explosion in these areas with its attendant high rate of commercial activities, influx and efflux of people to these suburbs and high rate of vehicular movement.

With an increase in the number of vehicles on the roads and traffic congestion, emission of greenhouse gases, which are unfavorable to human health, will be on the increase [9] Scientists, generally agree that increasing concentration of greenhouse gases in the atmosphere are causing changes in the earth's climate. Greenhouse gases include, among others, water vapor, carbon dioxide, methane, nitrous oxide, and halocarbons [10]. The timing, magnitude, and consequences of this temperature increase are not fully understood or agreed on, but it could lead to marked changes in sea level, precipitation, and storm patterns. The fact that the earth is getting warmer is not really in dispute among atmospheric scientists, the concern has rather been on the rate and cause of the continuous global warming, the effects or impacts of the warming on climate pattern or change, and consequently on life on earth $[11,12]$. The transportation sector is the most rapidly growing source of Greenhouse gas emission; that is, emissions of chemicals that have the potential to contribute to global warming [13]. These include chlorofluorocarbons, nitrous oxide, and carbon monoxide.

Air pollution is defined as the contamination of air by discharge of harmful substances, which can cause health problem including burning eyes and nose, itchy irritated throat and breathing problems [14]. It was also reported that some chemicals found in polluted air could cause cancer, birth defects brain and nerve damage, and long-term injury to the lungs and breathing passage in certain circumstances. The concentrations of such chemicals beyond a limit and an exposure over a certain period are extremely dangerous and can cause severe` injury or even death. Air pollution can be classified into natural air pollution which include wind-blown dust, volcanic ash, and gases, smoke and trace gases from forest fires, and anthropogenic air pollution which includes products of combustion such as Nitrogen Oxides $\left(\mathrm{NO}_{2}\right)$ Carbon dioxides $\left(\mathrm{CO}_{2}\right)$ and Sulphur dioxide $\left(\mathrm{SO}_{2}\right)$ [15]. Environmental pollution has been found to be highly correlated with contemporary transportation systems. Scott et al. (1982) [16] reported that automobiles produced as much as 60 percent of all air pollution in the United State.

In Europe and the United States, Small and Kazimi (1995) [17] reported that motor vehicle emission account for 32 to $98 \%$ of natural emission of Carbon monoxide, volatile organic compounds (primary hydro carbons) and Nitrogen oxide $\left(\mathrm{NO}_{2}\right)$. Furthermore, MacNee, W and Donaldson (1991) [18] had stated that transportation accounts for an important fraction of greenhouse gases (especially Carbon dioxide) emission. The transportation sector is the most rapidly growing source of greenhouse gas emissions; that is, emission of chemicals that have the potential to contribute to global warming [14].

Combustion engines contribute to greenhouse gas accumulation in the atmosphere and are responsible for climate changes. A sane, sober revision of vehicle use is long overdue. While ethanol has been championed as an alternative to petroleum fuels, it mainly helps to reduce dependency on oil producing countries. Ethanol or methanol can be blended with gasoline to reduce petroleum dependency. Gasoline engines can use up to $10 \%$ ethanol without modification. New "flex" engines can use higher percentages of ethanol up to $100 \%$. North American and European flex-fuel vehicles are optimized to run on a maximum blend of $15 \%$ gasoline with $85 \%$ ethanol (E85 fuel). The production of flex engine vehicles has increased, but the supply of flex fuel is limited [19].

Despite scientific evidence of climate change, governments in many affluent countries have avoided their responsibility to reduce emissions of greenhouse gases. The USA is the biggest emitter of greenhouse gases worldwide. US emissions increased to 7 billion tons of $\mathrm{CO}_{2}$ in 2004, $16 \%$ higher than emissions in the late 90's [20]. The UK did better reducing their emissions to about 0.6 billion tons, $14 \%$ below 1990 levels. An accurate analysis of total greenhouse gas emission is difficult or impossible to achieve since there are many variables and unknowns. Take the US estimates, for example, and pursue the argument that the US is also responsible for some emissions from other countries, which provide raw materials and manufacturing for the US economy. "U.S. businesses have off-shored more and more of the U.S. economies and $\mathrm{CO}_{2}$ emissions to parts of the world where the 
carbon intensity is higher but labor is cheaper. The U.S. has essentially off-shored its emission problem to the rest of the world, turning their economies into dumping grounds for our own air pollution."

In Nigeria, there has been rapid increase in urban population from 3,340,000 in 1950 to $38,159,000$ in 1990 [21] and by 1995, there were about $48 \%$ of the total population of Nigeria lives cities and towns [22]. In addition, the rate of population growth in the urban city of Abuja has been higher than that of rural areas due to migration of people from the rural to urban areas for better life. Apart from drastically reducing air quality and causing dangers to health, Vehicular pollution also majorly contributes to Global warming. This is an immediate concern, as climate change is becoming more and more prominent and rapid. Carbon dioxide is the major contribution to the greenhouse effects and much of $\mathrm{CO}_{2}$ emissions come from motor vehicles.

Because this research represents the attempt to quantify the inhalation intake of primary traffic-related air pollutants, there is need for a direct approach that clarifies underlying relationships, aid in elucidating causal connections, and permits the problem to be analytically tractable. Population density, passenger vehicle emissions, attributable ambient concentrations for primary pollutants, and the resulting attributable intake per capita will be analyzed. Below is the method for connecting these elements of the source intake relationship for primary pollutants from motor vehicles.

Population density has the potential to influence vehicle emissions [23] as well as the fraction of emissions inhaled by people [24, 25]. Population density is a key aspect of urban form, and one that can be influenced by urban planning. An increase in population density leads to an increase in both transportation emissions per $\mathrm{km}^{2}$ and per capital inhalation of emissions.

Therefore, this study is aimed at the measurement and comparison of the concentrations of some greenhouse gases at the study location during the peak and lean periods of traffic to the acceptable and tolerable standards of the Federal Ministry of Environment.

\subsection{The Study Area}

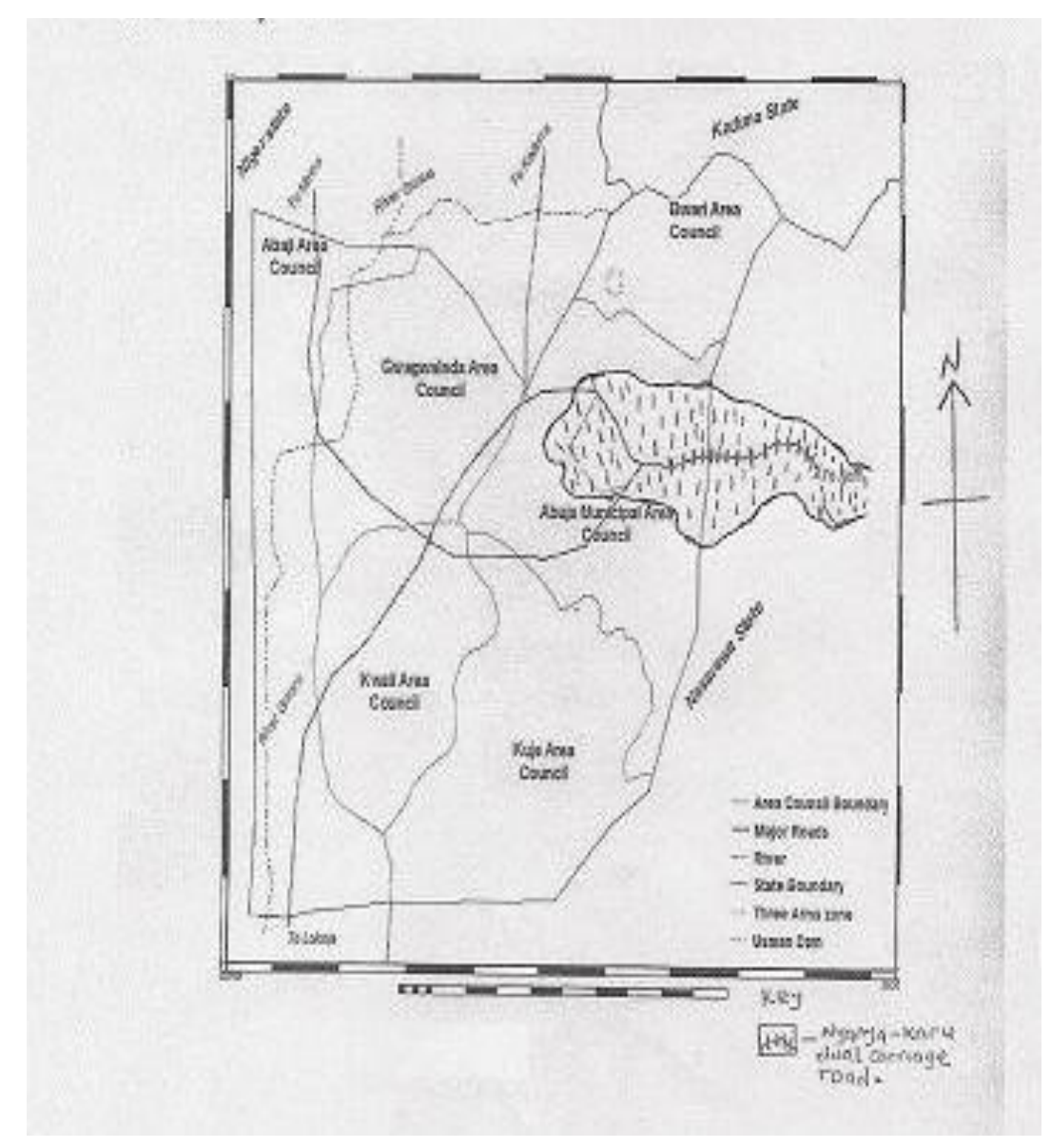

Fig1. Map showing the study area 


\subsection{Research Questions}

The researcher based her work on the following questions:

- What is the relationship between traffic volume during peak and off-peak periods?

- Are the air quality measurement values within the Federal Ministry of Environment limit?

- Do road users feel the effect of these greenhouse gases during traffic peak periods?

\subsection{Scope and Limitation}

This study examines the relationship between traffic flow and quantity of greenhouse gases emitted by cars. The study is restricted only to residents along old Nyanya and old Karu dual carriage road within the FCT (Figure 1). It does not extend to other neighborhood; neither does it stretch beyond old Nyanya and old Karu. However, this does not prevent the researcher from citing similar examples elsewhere. This research is not subjected to seasonal variations.

\section{Materials AND MethodS}

\subsection{Research Methodology}

Data were collected from primary and secondary sources. The primary data were collected by use of questionnaires, interviews, air quality measurements, and vehicular counts in the study axis while the secondary data were collected from website, academic research journals and other literatures related to the study. The operational measure of variable was used in the study, as well as Tables were used to evaluate the research questions.

\subsection{Reconnaissance Survey}

During the reconnaissance survey, the points for the vehicular counts and the gas measurement were chosen. Hospitals along the road were also picked in preparatory for the administration of questionnaires cum interviews. During reconnaissance, the researcher is able to observe some phenomena, which helped in the development of questionnaires.

\subsection{Research Design}

The research design chosen for this study is the survey research. This design is chosen because survey studies are used to document the nature, scope, dimension and direction of events, behavior and attitudes about person or things. Since this study requires collecting data on air quality as well as the challenges of hold-ups around Nyanya-Karu dual carriage road.

Vehicular counts was carried out during traffic peak and lean periods to establish the average number of vehicles that ply the road during the peak and lean periods of traffic while air pollutants like dust, $\mathrm{CO}, \mathrm{SO}_{2}, \mathrm{NO}_{2}$ and noise were also measured during these periods using hand held air quality measuring equipment.

\subsection{Population}

There are about 14,626 shops and household along the Nyanya -Karu dual carriage road. Projecting the figure to 2011 using exponential model at 3.5\% annual growth rate; it becomes 15,138 shops and houses representing the population of this research. From this population, questionnaire is administered to 300 shops and household along the road. Houses and shops picked along the road include those running from Karu junction down to police check point and to Mararaba last bus stop.

\subsection{Data Collection}

The method of data collection used was the qualitative method of data collection. Data collected were basically primary data which include in-situ measurement of air quality parameters, and vehicular count.

Vehicular count was carried out thrice in a week (Tuesdays, Thursdays and Fridays) for three months and the average was tabulated and analyzed. This was carried out during the peak periods of 7:00am to $10: 00 \mathrm{am}$ and from $4: 00 \mathrm{pm}$ to $6: 00 \mathrm{pm}$ at designated terminals, which were Nyanya before bridge, Karu Bridge and Abacha Barrack junction. 
Air quality assessment was carried out using the hand-held MSA Orion multiple gas alerts (USA). It measured $\mathrm{CO}, \mathrm{NO}_{2}$, and $\mathrm{SO}_{2}$ in parts per million (ppm) while particulate matter was measured using the Haze-Dust particulate monitor. The measurements were taken at the first traffic peak periods between 7:00am to 10:00am and the off-peak period between 12:00pm and 3:00pm when the road was free. The duration for this was four weeks.

\subsection{Data Analysis}

The data collected such as traffic flow (vehicular count), air quality measurement along the road were tabulated and analyzed. The air quality parameters were analyzed using the graphical method to compare the results of both the peak periods and the off-peak periods.

\section{RESULTS AND DISCUSSION}

The data presentation in Table 1 shows that an average of 44,039 cars plies the Nyanya-Karu axis towards the city centre between $6.30 \mathrm{am}$ and 10.00am on Tuesdays. It was also reported that 64 trucks ply this route during this time. In the evening also, an average of 12,242 cars and 127 trucks ply the Nyanya-karu axis from the city center between $4.00 \mathrm{pm}$ and $7.30 \mathrm{pm}$. Thus a total of 48,081 cars and truck ply the city to and fro during morning hours. Average traffic flows between the hours of $4.00 \mathrm{pm}$ and 7.00pm on Tuesdays for both cars and trucks was recorded as 19,714. This means that pollution possibilities along the route will be higher in the morning than evening as more vehicles ply the route in the morning than evening. This is in line with what Scott et al (1982) [16] said, that environmental pollution has been found to be highly correlated with contemporary transportation system.

Average vehicular count for Thursdays was lower than Tuesdays meaning that the traffic flow is not constant every day. Traffic flow for morning hours was recorded as 13,400 vehicles comprising cars and truck moving towards the city center while 4,636 vehicles are returning from the city centre during this time. In the evening also, 12,812 vehicles returns from the city center through NyanyaKaru axis while 4,791 vehicles move towards the city center through this same route.

Traffic flow in the morning on Fridays is very much higher as many people move towards the town to attend the mosque. An average of 14,447 vehicles move through the Nyanya- karu axis to the city center while an average of 4,049 vehicles were counted returning from the city Centre.

Table1: Average number of vehicles plying Nyanya-Karu expressway

\begin{tabular}{|l|l|l|l|l|l|}
\hline \multirow{4}{*}{ Days } & \multirow{2}{*}{$\begin{array}{c}\text { Mode of } \\
\text { Transport }\end{array}$} & \multicolumn{2}{c|}{ MORNING } & \multicolumn{2}{c|}{ EVENING } \\
\cline { 3 - 6 } & Towards City & \multicolumn{1}{c|}{ From City } & Towards City & \multicolumn{1}{c|}{ From City } \\
\hline \multirow{3}{*}{ Tuesday } & Cars & 44,039 & 3,871 & 7,224 & 12,242 \\
\cline { 2 - 6 } & Trucks & 64 & 107 & 121 & 127 \\
\hline \multirow{3}{*}{ Thursday } & Cars & 13,303 & 4,519 & 4,689 & 12,690 \\
\cline { 2 - 6 } & Trucks & 97 & 117 & 102 & 122 \\
\hline \multirow{2}{*}{ Friday } & Cars & 14,325 & 3,952 & 5,274 & 12,406 \\
\cline { 2 - 6 } & Trucks & 122 & 97 & 94 & 104 \\
\hline
\end{tabular}

Source: Fieldwork, 2011/2012

The impact of this traffic on the environment is the pollutants released by these vehicles during the traffic peak period most especially in the morning and evening when people are struggling to get to work and returning home. The amount of carbon monoxide and other pollutants emitted into the environment during these periods are higher than they ought to be according to Federal Ministry of Environment's maximum permissible limit for human inhalation, which include:-CO (10ppm), PM $\left(250 \mathrm{mg} / \mathrm{m}^{3}\right), \mathrm{NO}_{2}(0.6 \mathrm{ppm}), \mathrm{SO}_{2}(0.1 \mathrm{ppm})$, and Noise $(90 \mathrm{dBa})$.

From Table 1, it is discovered that the number of vehicles increases during the morning hours and decreases towards evenings as a result of the number of people moving to the city centre to their work places and other businesses. Traffic also increases later in the evenings from $4.00 \mathrm{pm}$ to about $7.30 \mathrm{pm}$ as a result of people returning back from their work places and business. The Nyanya-Karu dual carriage way is a major road that leads to other states like Nasarawa, Benue, Plateau, Cross-River etc, as such public transport vehicles also ply this road. This also explains the reason for the increased carbon-monoxide (CO) levels in the mornings and other gases especially particulate matter. 
The Volume of Vehicular Greenhouse gas Emissions along a Dual Carriage Road in North-Central Nigeria: A Survey Study

The concentrations of major vehicular pollutants (Table 2) were measured in-situ using hand-held MSA Orion multiple gas alert. The equipment measures $\mathrm{CO}, \mathrm{NO}_{2}$, and $\mathrm{CO}_{2}$ in ppm while particulate matter was measured using haze dust particulate matter. The measurements were taken at traffic peak periods, between the hours of 6.30am and 10.00am while traffic off peak measurements was taken between $12.00 \mathrm{pm}$ and $3.00 \mathrm{pm}$ when the road was free. For the four weeks, when measurements were carried out, Tuesdays and Thursdays were chosen as sampling days with sampling carried out twice a day i.e. peak and off-peak periods. These days were chosen out of other days because most people ply the road at that time. By Mondays and Fridays, most people would not have been back from their weekend journeys

Table2. Average Air quality assessment along Nyanya-Karu dual carriage way

\begin{tabular}{|c|c|c|c|c|c|c|c|c|c|c|c|c|c|c|c|c|c|}
\hline \multirow[t]{4}{*}{$\mathbf{S} / \mathbf{N}$} & \multirow[t]{4}{*}{ Parameter } & \multirow{2}{*}{\multicolumn{4}{|c|}{$\begin{array}{c}\text { December } 2011 \\
\text { WEEK } 1\end{array}$}} & \multirow{2}{*}{\multicolumn{4}{|c|}{$\frac{\text { December } 2011}{\text { WEEK } 2}$}} & \multirow{2}{*}{\multicolumn{4}{|c|}{$\frac{\text { January, } 2012}{\text { WEEK } 3}$}} & \multicolumn{4}{|c|}{ January, 2012} \\
\hline & & & & & & & & & & & & & & & WEE & K 4 & \\
\hline & & Tuesc & day & Thur & sday & Tues & day & Thur & sday & Tues & day & Thur & sday & Tuesc & & Thur & sday \\
\hline & & 6-12- & & $8-12$ & 11 & $13-1$ & -11 & $15-1$ & $2-11$ & $24-0$ & $1-12$ & $5-01$ & -12 & $31-01$ & 2012 & $19-0$ & $1-12$ \\
\hline & & \begin{tabular}{|l|}
$8: 24$ \\
am
\end{tabular} & $\begin{array}{l}1: 29 \\
\mathrm{pm}\end{array}$ & $\begin{array}{l}8: 20 \\
\text { am }\end{array}$ & $\begin{array}{l}1: 33 \\
\mathrm{pm}\end{array}$ & $\begin{array}{l}8: 15 \\
\text { am }\end{array}$ & $\begin{array}{l}1: 20 \\
\mathrm{pm}\end{array}$ & $\begin{array}{l}8: 25 \\
\mathrm{am}\end{array}$ & $\begin{array}{l}1: 27 \\
\mathrm{pm}\end{array}$ & $\begin{array}{l}8: 31 \\
\mathrm{am}\end{array}$ & $\begin{array}{l}1: 20 \\
\mathrm{pm}\end{array}$ & $\begin{array}{l}8: 20 \\
\text { am }\end{array}$ & $\begin{array}{l}1: 36 \\
\mathrm{pm}\end{array}$ & $\begin{array}{l}8: 20 \mathrm{a} \\
\mathrm{m}\end{array}$ & $\begin{array}{l}1: 33 p \\
m\end{array}$ & $\begin{array}{l}9: 15 \\
\text { am }\end{array}$ & $\begin{array}{l}1: 30 \\
\text { pm }\end{array}$ \\
\hline 1 & Noise(dBa) & 78.8 & 68.9 & 76.8 & 61.5 & 66.4 & 61.0 & 68.8 & 62.5 & 76.6 & 71.3 & 91.2 & 65.5 & 63.6 & 61.8 & 76.5 & 62.1 \\
\hline 2 & $\begin{array}{l}\text { Particulate m } \\
\text { atter(mg/m3) }\end{array}$ & 0.48 & 0.41 & 0.65 & 0.59 & 0.43 & 0.35 & 0.33 & 0.30 & 0.48 & 0.43 & 0.34 & 0.31 & 0.48 & 0.29 & 0.63 & 0.53 \\
\hline 3 & $\mathrm{CO}(\mathrm{ppm})$ & 4 & 2 & 3 & 2 & 3 & 2 & 3 & 3 & 3 & 2 & 3 & 1 & 3 & 1 & 3 & 2 \\
\hline 4 & $\mathrm{NO}_{2}\left(\mathrm{ppm}_{)}\right.$ & 0.7 & 0.3 & 0.4 & 0.3 & 0.4 & 0.3 & 0.2 & 0.2 & 0.3 & 0.2 & 0.1 & 0.1 & 0.2 & 0.1 & 0.2 & 0.1 \\
\hline 5 & $\mathrm{SO}_{2(} \mathrm{ppm}_{)}$ & 0.4 & 0.2 & 0.3 & 0.2 & 0.3 & 0.3 & 0.2 & 0.1 & 0.2 & 0.2 & 0.1 & 0.1 & 0.2 & 0.1 & 0.3 & 0.1 \\
\hline
\end{tabular}

Source: Fieldwork, 2011/2012

Results presented in Table 2 shows that noise pollution is higher during traffic peak period with an average of $71 \mathrm{~dB}$ which is more than the maximum permissible limit for human inhalation. It decreases during the off-peak period which is around $1.00 \mathrm{pm}$ with an average measurement of 63.6dB. Although, as at Thursday, $5^{\text {th }}$ of January 2012; it exceeded the Federal Ministry of Environment maximum permissible limit for human inhalation. This could pose a danger to the human ocular nerves if persisted.

Carbon-monoxide measurements (Figure 2) for both peak and off peak periods are also presented. It shows that the value for traffic peak period is higher than that of off-peak period for all the days except the Thursday of week 2 in December 2011 when both peak and off-peak have 3ppm during the two measurements.

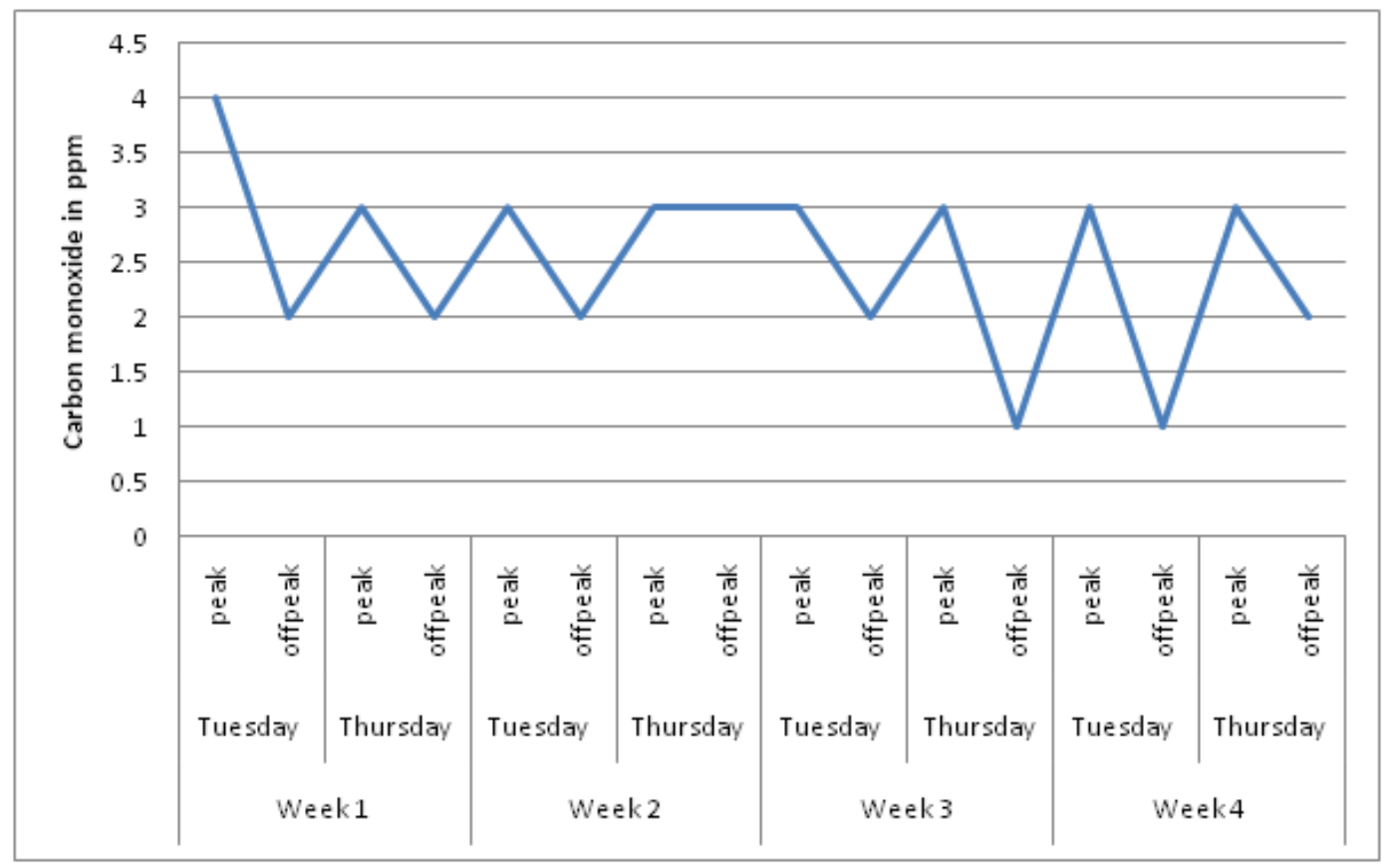

Fig2. Trend of carbon monoxide during peak and off-peak periods 
The Volume of Vehicular Greenhouse gas Emissions along a Dual Carriage Road in North-Central Nigeria: A Survey Study

Results of Nitrogen-dioxide (Fig 3) measurements has the same trend as carbon monoxide in the study area as the values recorded for peak traffic periods are higher than that of off-peak periods except for one or two days when both peak and off-peak periods have the same values.

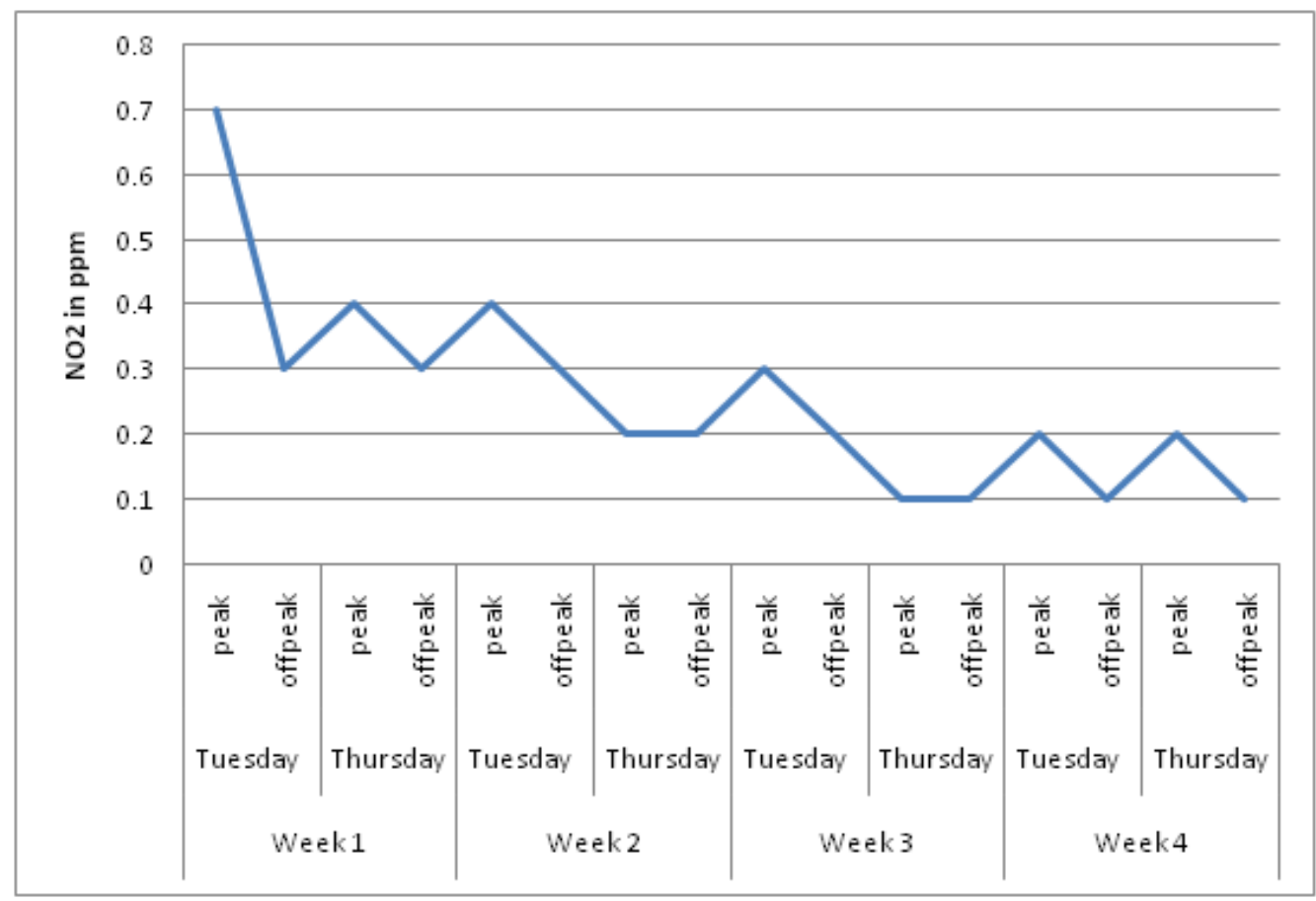

Fig3. Trend of Nitrogen-dioxide during peak and off-peak periods

The result of Sulphur dioxide (Fig 4) is not too different from what was obtained in $\mathrm{CO}$ and $\mathrm{NO}_{2}$ as the concentration is higher during peak periods and comes down slightly during off-peak periods. The reason for this could be attributed to the increase in number of vehicles during the peak periods as such increase in vehicular emissions. This could be attributed to the increasing rate of upper respiratory tract infections in the study area.

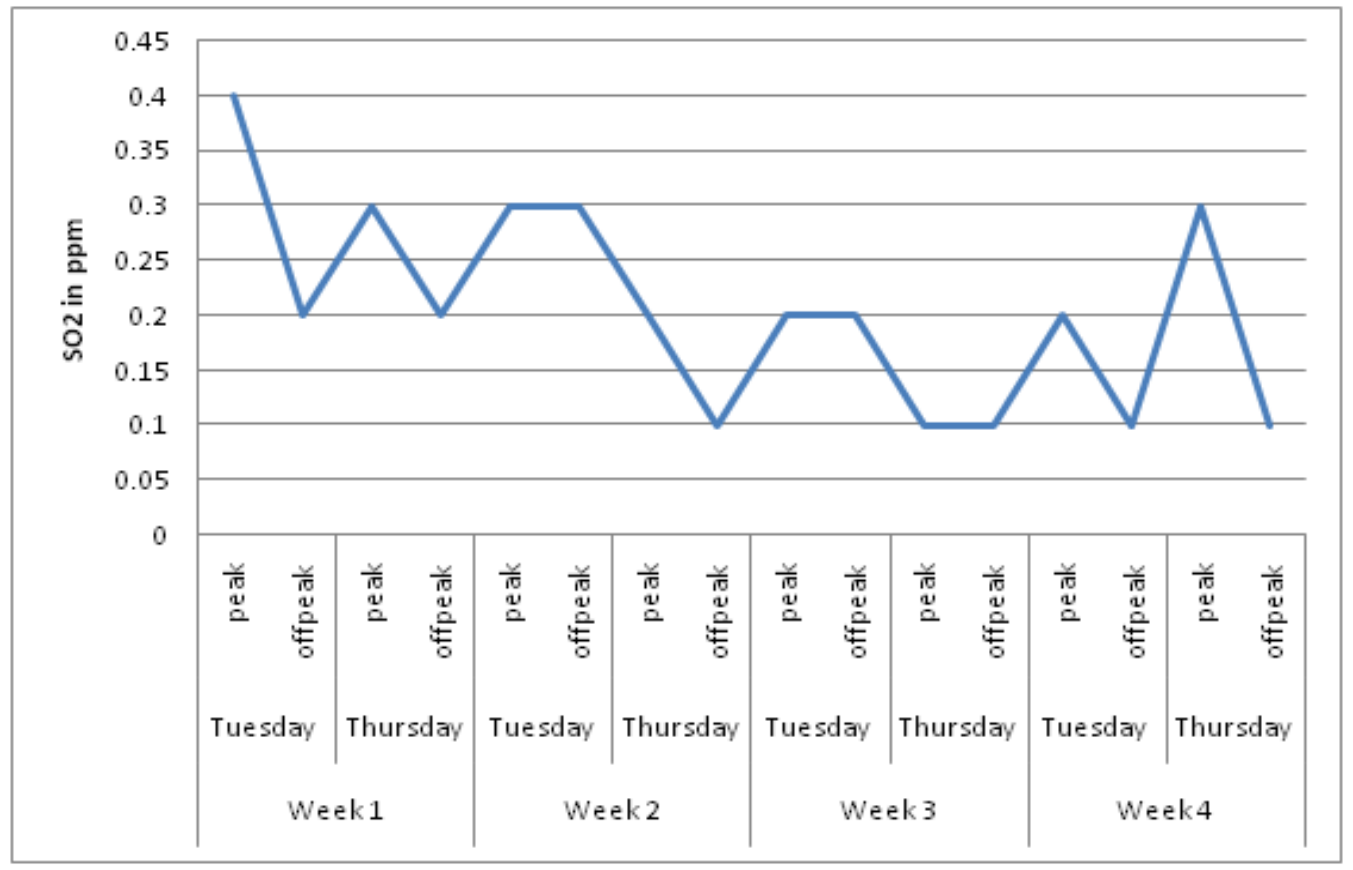

Fig4. Trend of sulphur-dioxide during peak and off-peak periods

The result of air quality measurements in Table 4 show that noise, particulate matter, $\mathrm{CO}, \mathrm{NO}_{2}$ and $\mathrm{SO}_{2}$ are higher during the peak period while the reverse is the case during the off-peak period. Obviously, this is as a result of the increase in the number of vehicles during the peak period as seen 
from the result of the vehicular count. However, from the results, carbon-monoxide is the highest emitted gas, which could have grave implication to human health.

\section{CONCLuSion}

From the findings of this research work, the following conclusions can be made:

- Traffic congestion during traffic peak periods contributes greatly to high concentration of $\mathrm{NO}_{2}, \mathrm{SO}_{2}, \mathrm{CO}$ and $\mathrm{pm}$ in the atmosphere than off-peak periods.

- The concentration of $\mathrm{NO}_{2}, \mathrm{SO}_{2}, \mathrm{CO}$ and pm during traffic peak periods exceeds the maximum permissible limit of the Federal Ministry of Environment.

- The number of vehicles plying Nyanya-Karu route doubles the numbers counted during offpeak periods.

\section{REFERENCES}

[1] Peace H., Owen B. and Raper D.W., Identifying the contribution of different urban highway air pollution sources. Science Total Environ. 334-335, 347-357 (2004).

[2] Zeka A., Zanobetti A. and Schwartz J., Short term effects of particulate matter on cause specific mortality: effects of lags and modification by city characteristics. Environ Med. 62, 718-725 (2005).

[3] Campbell M. E,, Benson B. A. and Munir M. A., Urban air quality and human health .Toronto, 86, 351 357 (1995).

[4] Hoek G., Meliefste K., Cyrs J., Lewne M., Bellander T. and Brauer M., Spatial variability of fine particle concentration in three European areas. Atmosphere Environment. 36, 4077-4088 (2002).

[5] Longley I. D., Gallagber M.W., Dorsey J. R., Flynn M., Bower K. N. and Allan J. D., Street canyons aerosol pollutant transport measurements. Science Total Environ. 334-335, 327-336 (2004).

[6] Karpoof T. and Adepoju E., Socio-Economic Implications of Urban Renewal Programmes In South-West Nigeria: The Case of Ogun, Oyo And Osun States. Nigerian Institute of Social and Economic Research, Ibadan, Nigeria. (2017) (https;//niser.gov.ng; accessed 25th March, 2018)

[7] Gee I. L. and Raper D. W., Commuter exposure to respirable particles inside buses and by bicycle. Total Environment, 235, 403-405 (1999).

[8] Water and Dam Services Company - WADSCO, Gurara Water Transfer to FCT - Water Conveyance Pipeline. 2014, https://ppp.icrc.gov.ng (accessed 20th April 2018).

[9] Ziskind R. A., Fite K. and Mage D. T., Pilot field studies: carbon monoxide exposure monitoring in the general. Environ Int, 8, 283-293 (1982).

[10] Tomei F., Ghittori S., Imbriani M., Pavanello S., Carere A., Marcon F.,. Environmental and biological monitoring of traffic wardens from the city of Rome. Occup Med; 51:198-203 (2001).

[11] Enger, E. D. and Smith, B. F., Environmental Science; A study of Interrelationships, 10th Edition, New York, USA. (2006).

[12] Nathanson J. A., Basic Environmental Techology "Water Supply, 'Waste Management and Pollution Control" 4th, Prentice-Hall Jersey, USA (2006).

[13] Intergovernmental Panel on Climate Change, IPCC., Fifth Assessment Report of World Meteorological Organization. Geneva. United Nations Environmental Programme, 2014; https://www.ipcc.ch/pdf/ assessment-report (cited 12th April 2018).

[14] USEPA. Exposure factors handbook. Office of Research and Development, National Center for Environmental. Assessment, U.S Environmental Protection Agency. Washington DC, 2011; https://www.nrc.gov/docs (cited 5th May 2018).

[15] Dragonieri S., Musti M., Izzo C., Esposito L. M., Barbaro M. and Rta O.,. Sputum induced cellularity in a group of traffic policemen. Brazil, 367:433-436 (2006).

[16] Scott A., Lyon A. P, Osmos D.A., Air pollution in U.S.A .113-12 (1982).

[17] Small C. and Kazimi A. R., Motor vehicle emissions in Ukraine, 45, 80. Ukraine (1995)..

[18] MacNee W. and Donaldson K., Exacerbations on COPD: environmental mechanisms. 117: 390-397 (2000).

[19] Yang Q., Chen Y., Krewski D., Burnett R. T., Shi Y. and McGrail, K.M., Effect of short-term exposure to low level of gaseous pollutants on chronic obstructive pulmonary disease hospitalizations, Environ Res; 99: 99-105 (2005).

[20] Schikowski T., Sugiri D., Ranfit U., Gehring U., Heinrich J. and Wichmann H., Long term air pollution exposure and living close to busy roads are associated with COPD in women. 6:152 (2005). 
The Volume of Vehicular Greenhouse gas Emissions along a Dual Carriage Road in North-Central Nigeria: A Survey Study

[21] UNO (1995), Framework Convention on Climate Change. http://sussex.ac.uk.Accessed in March 2010. Nigeria's current estimated population. http://population.gov.ng (Acessed April 2018).

[22] Holtzclaw J., clear R., Dittmar H., Goldstein D.and Daas P. Location efficiency: neighborhoods and socio-economic characteristics determine auto ownership and use - studies in chicago, los Angeles and san Francisco. Transportation planning and Technology 25, 1-27 (2002).

[23] Lai A. C. K.,Thatcher T..L. and Nazar F.W., Inhalation transfer factor for air pollution health risk assessment. Journal of the air and waste management Association 50, 1688-1699 (2002).

[24] Randem B. G., Ulvestad B., Burstyn I. and Kongerud J., Respiratory symptoms and airflow limitation in asphalt workers. Occup Environ Med. 61:367-369 (2004).

\section{AUTHOR'S BIOGRAPHY}

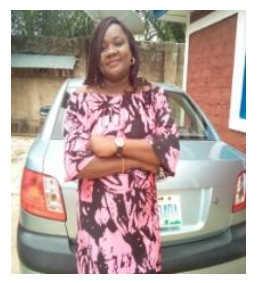

Elizabeth D Ebeshi is $\mathrm{PhD}$ student in Geography Department, Nasarawa State University Keffi, Nasarawa State, Nigeria, with special emphasis in Environment Studies and Management.

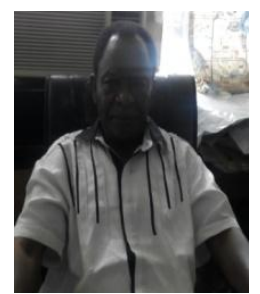

Prof. Olusegun Ekanade is a Biographer with special emphasis on Environment Studies and Management. He is at present in the Department of Geography, Osogbo, Osun State, Nigeraia.

Citation: Elizabeth D. Ebeshi, Olusegun Ekanade. "The Volume of Vehicular Greenhouse gas Emissions along a Dual Carriage Road in North-Central Nigeria: A Survey Study”. International Journal of Research in Geography. vol 4, no. 3, 2018, pp. 1-9 doi: http://dx.doi.org/10.20431/2454-8685.0403001.

Copyright: (C) 2018 Authors. This is an open-access article distributed under the terms of the Creative Commons Attribution License, which permits unrestricted use, distribution, and reproduction in any medium, provided the original author and source are credited. 